\title{
Dietary inclusion effect of various levels of jack mackerel meal on the growth performance, feed efficiency and whole body composition of rockfish (Sebastes schlegeli)
}

\author{
Seong II Baek', Sung Hwoan $\mathrm{Cho}^{2,}{ }^{2}$, Hee Sung Kim ${ }^{3}$ \\ ${ }^{1}$ Department of Convergence Study on the Ocean Science and Technology, Korea Maritime and Ocean University, Busan 49112, Korea \\ ${ }^{2}$ Division of Marine Bioscience, Korea Maritime and Ocean University, Busan 49112, Korea \\ ${ }^{3}$ Department of Seafood and Aquaculture Science, College of Marine Science, Gyeongsang National University, Tongyeong 53064, Korea
}

\begin{abstract}
Inclusion effect of various levels of jack mackerel meal (JMM) acting as feed attractants and/or stimulants in diets on the growth, feed consumption, feed utilization and whole body composition of rockfish was investigated. Three hundred juvenile rockfish were randomly allocated into 15 flow-through tanks. Five experimental diets supplemented with JMM at $0 \%, 1 \%, 3 \%, 5 \%$, and $10 \%$ at the expense of anchovy meal were prepared and referred to as the JMM0, JMM1, JMM3, JMM5, and JMM10 diets, respectively. Weight gain, specific growth rate (SGR) and feed consumption of fish tended to improve with dietary levels of JMM. The greatest weight gain, SGR and feed consumption were observed in fish fed the JMM10 diet, followed by the JMM5, JMM3, JMM1, and JMMO diets, in that order. Condition factor (CF) of fish tended to improve with dietary inclusion levels of JMM. Growth performance, feed consumption and CF of fish tended to improve with dietary inclusion levels of JMM ranging from $0 \%$ to $10 \%$.
\end{abstract}

Keywords: Rockfish (Sebastes schlegeli), Jack mackerel meal (JMM), Feed stimulants, Feed consumption, Condition factor

\section{Introduction}

Rockfish (Sebastes schlegeli Hilgendorf 1880) has become one of the most commercially important marine aquaculture fish species in Korea since 1980s due to its fast growth and high disease resistance. Its annual aquaculture production reached 21,571 metric tons in Korea in 2020 (KOSIS, 2021). As rockfish farmers prefer feeding their fish on moisture pellet (MP), such as frozen fish or the mixture of frozen fish and binder to feeding their fish on formulated feed (FF), such as extruded pellet and dry pellet in Korea, a total amount of 140,192 metric tons of MP was used, but only 16,264 metric tons for FF in 2019 (KOSIS, 2021). A reason of higher adoption of MP rather than FF by fish farmers in Korea is a misbelief that rockfish feeding on the

Received: Jun 23, 2021 Revised: Aug 20, 2021 Accepted: Sep 1, 2021

${ }^{*}$ Corresponding author: Sung Hwoan Cho

Division of Marine Bioscience, Korea Maritime and Ocean University, Busan 49112, Korea

Tel: +82-51-410-4755, Fax: +82-51-404-4750, E-mail: chosunh@kmou.ac.kr

This is an Open Access article distributed under the terms of the Creative Commons Attribution Non-Commercial License (http://creativecommons.org/licenses/by$\mathrm{nc} / 4.0 /$ ) which permits unrestricted non-commercial use, distribution, and reproduction in any medium, provided the original work is properly cited.

Copyright ( $) 2021$ The Korean Society of Fisheries and Aquatic Science 
former tend to consume more feed than the latter because the former is likely to contain more feed attractants and/or stimulants than the latter.

Nevertheless, application of FF is highly recommendable for sustainable and eco-friend fish culture worldwide in terms of prevention of disease spread, low storage and fish production costs, and little discharged effluent from fish farms adopting FF (Cho et al., 2005; Ekanem, 1996; Sun et al., 2006). Therefore, dietary supplementation of feed attractants and/or stimulants to rockfish is highly desirable for fish farmers to adopt FF to raise their fish instead of MP.

In our earlier study (Kim et al., 2019), jack mackerel meal (JMM) being rich in free histidine and leucine showed the strongest attractiveness to rockfish among 16 crude feed ingredients, followed by sardine meal, squid meal, pollock meal and shrimp meal. In addition, dietary supplementation of 5\% JMM at the expense of anchovy meal showing moderate attractiveness to rockfish achieved the greatest growth performance and condition factor (CF) directly reflected from improved feed consumption (palatability) (Kim \& Cho, 2019). Therefore, inclusion of feed ingredient having strong attractiveness to a targeting fish in diet is one of the most reliable and sustainable aquaculture techniques to accelerate growth (production) of fish resulted from improved feed consumption.

It is critical for fish farmer to understand the factors influencing feed consumption by fish to achieve efficient growth of fish in an intensive aquaculture system. Dietary manipulation of feed ingredients to maximize feed intake by fish is the best way for fish farmer to improve growth of fish and bring about high benefits from fish farm because feed is one of the most expensive and substantial costs in aquaculture operation, accounting for over $50 \%$ of total operating cost (Abidi \& Khan, 2008). Application of feed attractants and/or stimulants in feed, therefore, is an effective aquaculture technique to improve feed intake, but minimize feed waste in terms of improved feed consumption (palatability) of fish (Lee \& Meyers, 1996).

Dietary inclusion of krill hydrolysate, squid viscera meal, mussel meal and blood meal effectively improved feed consumption of fish (Kolkovski et al., 2000; Mai et al., 2006; Mongile et al., 2015; Nagel et al., 2014). Kader et al. (2010) also showed that administration of crude feed ingredient, such as $10 \%$ fish soluble, $10 \%$ krill meal and $10 \%$ squid meal in diets acting as feed stimulants improved weight gain and feed consumption of red sea bream (Pagrus major), in particular, their combination at $15 \%$ (5\% for each) improved growth outstand- ingly. Red sea bream fed a diet substituting 100\% fish meal (FM) with dehulled soybean meal supplemented with feed attractants (the combined 10\% fish soluble, 5\% krill meal and 5\% squid meal) achieved comparable growth to fish fed a FM-based diet (Kader et al., 2012).

Based on evaluation of attractability of the synthetic chemicals identified in the extracts of prey or feed to fish was determined by electro(neuro)physiological study in the past (Kasumyan \& Døving, 2003; Kasumyan \& Morsi, 1996; Mackie, 1982; Miyasaka \& Harada, 2002; Yacoob \& Browman, 2007), feed attractants are commonly developed. Nevertheless, feasibility of practical application of the synthetic chemicals showing high attractiveness to targeting fish is still controversial. Therefore, manipulation of feed ingredient rather than the synthetic chemicals showing high attractiveness to a targeting fish in feed is a practical and sustainable technique to improve growth of fish resulted from improved feed consumption (palatability). Nagel et al. (2014) reported that an increased amount of supplemented freeze-dried blue mussel (Mytilus edulis) meal improved feed consumption and weight gain of turbot (Psetta maxima) fed diets substituting 75\% FM with rapeseed protein concentrate when 50\% and 75\% FM were substituted with rapeseed protein concentrate supplemented with various $(2 \%, 4 \%$, and $8 \%$ ) levels of freeze-dried blue mussel meal, and concluded that administration of freeze-dried blue mussel meal could improve palatability of diets.

Feed attractants and/or stimulants vary based on fish species, type, and dose of feed attractants (Carr et al., 1996; Olsén \& Lundh, 2016; Yacoob \& Browman, 2007). For instance, blue mussel extracts acted as feed attractants and/or stimulants in a bottom feeding carnivorous Dover sole (Solea solea) (Mackie, 1982), but did as feed deterrents for omnivorous crucian carp (Carassius carassius), which do not feed on mussel in their natural surroundings (Olsén \& Lundh, 2016).

In this study, we elucidate inclusion effect of various levels of JMM acting as feed attractants and/or stimulants in diets on the growth, feed consumption, feed efficiency and whole body composition of rockfish.

\section{Materials and Methods}

\section{Preparation of the experimental fish}

Juvenile rockfish were purchased from a private fish hatchery and acclimated to the experimental conditions for 2 week before start of the feeding trial. During the 2 -week acclimation pe- 
riod, fish were fed with a commercial extruded pellet (Woosung Feed, Daejeon, Korea) twice a day at a ratio of 2\%-3\% biomass of fish. Three hundred fish (initial body weight of $5.3 \mathrm{~g}$ ) were randomly allocated into 15, $50 \mathrm{~L}$ flow-through tanks (water volume: 40 L) (20 fish/tank). Sand-filtered seawater was supplied and the flow rate of water was $4.2 \mathrm{~L} / \mathrm{min} /$ tank. Aeration was properly supplied into each tank and water temperature ranged from $17.6^{\circ} \mathrm{C}$ to $23.9^{\circ} \mathrm{C}$ (mean \pm SD: $20.9 \pm 1.644^{\circ} \mathrm{C}$ ) throughout the 8 -week feeding trial.

\section{Preparation of the experimental diets}

Five experimental diets were prepared (Table 1). Fifty five percent anchovy meal and $10.5 \%$ fermented soybean meal were used as the protein source in the JMM0 diet. Twenty three percent wheat flour and $4.5 \%$ fish and $4.5 \%$ soybean oils were used as the carbohydrate and lipid sources, respectively, in the JMM0 diet. One, 3\%, 5\%, and 10\% JMM were supplemented at the expense of anchovy meal, referred to as the JMM1, JMM3, JMM5, and JMM10 diets, respectively. All experimental diets were at isonitrogenic (52.0\%) and isolipidic (15.7\%). The experimental diets were prepared to fulfill nutrient requirements of rockfish (Kim et al., 2001, 2007).

The ingredients of the experimental diets were mixed with water at a ratio of 3:1 and pelletized by lab pellet-extruder (Dongsung Mechanics, Busan, Korea). The experimental diets were dried at room temperature overnight and stored in $-20^{\circ} \mathrm{C}$ until use. The experimental diets were randomly assigned to triplicate groups of fish and hand-fed to visual satiety twice a day (0900 and 1700) for 7 days a week during 8 weeks. Appropriate size pellet was fed as fish grew. The experimental diets were carefully fed to fish to minimize feed waste. Amount of feed supply was recorded for each tank, but uneaten feed was not collected. The tanks were siphon-cleaned daily.

\section{Analysis of the experimental diets and whole body fish}

At the end of the 8-week feeding trial, total biomass of each tank was weighed collectively. Five fish from each tank were randomly sampled for the whole body composition analysis. In addition, 10 fish from each tank were sampled for analysis of individual fish weight, total length and liver weight, CF and

Table 1. Ingredients of the experimental diets containing various concentrations of jack mackerel meal (JMM) (DM basis \%)

\begin{tabular}{|c|c|c|c|c|c|}
\hline & \multicolumn{5}{|c|}{ Experimental diets } \\
\hline & JMMO & JMM1 & JMM3 & JMM5 & JMM10 \\
\hline \multicolumn{6}{|l|}{ Ingredients (\%) } \\
\hline Anchovy meal ${ }^{1)}$ (CP: 72.3\%, CL: 9.7\%) & 55 & 54 & 52 & 50 & 45 \\
\hline Jack mackerel meal (JMM) ${ }^{1)}(\mathrm{CP}: 74.2 \%, \mathrm{CL}: 8.6 \%)$ & & 1 & 3 & 5 & 10 \\
\hline Fermented soybean meal ${ }^{2)}$ & 10.5 & 10.5 & 10.5 & 10.5 & 10.5 \\
\hline Wheat flour & 23 & 23 & 23 & 23 & 23 \\
\hline Fish oil & 4.5 & 4.5 & 4.5 & 4.5 & 4.5 \\
\hline Soybean oil & 4.5 & 4.5 & 4.5 & 4.5 & 4.5 \\
\hline Vitamin premix ${ }^{3)}$ & 1 & 1 & 1 & 1 & 1 \\
\hline Mineral premix ${ }^{4)}$ & 1 & 1 & 1 & 1 & 1 \\
\hline Choline & 0.5 & 0.5 & 0.5 & 0.5 & 0.5 \\
\hline \multicolumn{6}{|l|}{ Nutrients (\%) } \\
\hline Dry matter & 95.9 & 96.1 & 96.0 & 96.1 & 96.1 \\
\hline $\mathrm{CP}$ & 52.1 & 52.0 & 52.0 & 52.0 & 52.0 \\
\hline $\mathrm{CL}$ & 15.7 & 15.5 & 15.6 & 15.8 & 15.7 \\
\hline Ash & 10.5 & 10.4 & 10.4 & 10.4 & 10.5 \\
\hline
\end{tabular}

${ }^{1)}$ Anchovy meal (US\$ 1,750-1,800/ton) and ") jack mackerel meal (JMM) (US\$2,450-2,500/ton) were bought from Abank (Seoul, Korea).

${ }^{2)}$ Fermented soybean meal was supplied by CJ CheilJedang (Seoul, Korea).

${ }^{3)}$ Vitamin premix contained the following amount which were diluted in cellulose (g/kg mix): L-ascorbic acid, 121.2; DL-a-tocopheryl acetate, 18.8; thiamin hydrochloride, 2.7; riboflavin, 9.1; pyridoxine hydrochloride, 1.8; niacin, 36.4; Ca-D-pantothenate, 12.7; myo-inositol, 181.8; D-biotin, 0.27; folic acid, 0.68; p-aminobenzoic acid, 18.2; menadione, 1.8; retinyl acetate, 0.73; cholecalciferol, 0.003 ; cyanocobalamin, 0.003 .

${ }^{4)}$ Mineral premix contained the following ingredients (g/kg mix): $\mathrm{MgSO}_{4} \cdot 7 \mathrm{H}_{2} \mathrm{O}, 80.0 ; \mathrm{NaH}_{2} \mathrm{PO}_{4} \cdot 2 \mathrm{H}_{2} \mathrm{O}, 370.0 ; \mathrm{KCl}, 130.0 ;$ ferric citrate, 40.0; $\mathrm{ZnSO}{ }_{4} \cdot 7 \mathrm{H}_{2} \mathrm{O}, 20.0 ; \mathrm{Ca}-\mathrm{lactate}, 356.5 ; \mathrm{CuCl}, 0.2$; $\mathrm{AlCl}_{3} \cdot 6 \mathrm{H}_{2} \mathrm{O}, 0.15 ; \mathrm{Kl}, 0.15 ; \mathrm{Na}_{2} \mathrm{Se}_{2} \mathrm{O}_{3}, 0.01 ; \mathrm{MnSO}_{4} \cdot \mathrm{H}_{2} \mathrm{O}, 2.0 ; \mathrm{CoCl}_{2} \cdot 6 \mathrm{H}_{2} \mathrm{O}, 1.0$.

$\mathrm{CP}$, crude protein; $\mathrm{CL}$, crude lipid. 
hepatosomatic index (HSI).

Experimental diets and homogenized fish body samples were analyzed for the chemical composition based on the AOAC standard method (AOAC, 1990). Moisture content was determined by oven drying at $105^{\circ} \mathrm{C}$ for $24 \mathrm{~h}$ and crude protein was determined by the Kjeldahl method (Kjeltec 2100 Distillation Unit, Foss Tecator, Hoganas, Sweden). Crude lipid was determined using an ether-extraction method (Soxtec TM 2043 Fat Extraction System, Foss Tecator, Hoeganaes, Sweden) and ash was determined using a muffle furnace at $550{ }^{\circ} \mathrm{C}$ for $4 \mathrm{~h}$.

\section{Calculation used}

The following equations were calculated: specific growth rate $(\mathrm{SGR}, \% /$ day $)=($ Ln final weight of fish $-\mathrm{Ln}$ initial weight of fish) $\times 100 /$ days of feeding trial; feed efficiency ratio $($ FER $)=$ weight gain of fish/feed consumption; protein efficiency ratio (PER) = weight gain of fish/protein consumption; protein retention $(\mathrm{PR})=$ protein gain $\times 100 /$ protein consumption; $\mathrm{CF}$ $\left(\mathrm{g} / \mathrm{cm}^{3}\right)=$ body weight $\times 100 /$ total length $^{3}$; and hepatosomatic index $($ HSI $)=$ liver weight $\times 100 /$ body weight.

\section{Statistical analysis}

Statistical analyses were applied using SPSS 17.0 for Windows (SPSS, Chicago, IL, USA). Data were subjected to a one-way analysis of variance (ANOVA), followed by the Duncan's multiple range test. Additionally, regression analysis was performed between dietary levels of JMM and weight gain, SGR, feed consumption and CF of fish at the termination of 8-week feeding trial.

\section{Results}

Survival, weight gain and SGR of rockfish fed the experimental diets containing various levels of JMM for 8 weeks are presented in Table 2. All fish survived at the end of the feeding trial. Weight gain and SGR of fish tended to improve with an increased inclusion levels of JMM in diets. The following correlation between the weight gain of fish (Y) and JMM (X) concentrations in diets was obtained: $\mathrm{Y}=-0.0111 \mathrm{X}^{2}+0.5859 \mathrm{X}$ $+18.0480, \mathrm{R}^{2}=0.9830(p<0.0001)$ and $\mathrm{Y} \max =26.0(\mathrm{X}$ concentration), and $Y=-0.0010 \mathrm{X}^{2}-0.0434 \mathrm{X}+2.6516, \mathrm{R}^{2}=0.9797$ $(p<0.0001)$ and $\mathrm{Y} \max =21.7$ (X concentration) for correlation between SGR of fish (Y) and JMM (X) concentrations in diets, respectively.

Feed consumption, feed efficiency, CF and HSI of rockfish fed the experimental diets containing various concentrations of JMM for 8 weeks are presented in Table 3. Feed consumption of fish tended to increase with an increased levels of JMM in diets. The following correlation between feed consumption (Y) and JMM $(\mathrm{X})$ concentrations in diets was obtained: $\mathrm{Y}=-0.0127 \mathrm{X}^{2}+$ $0.5810 \mathrm{X}+17.4140, \mathrm{R}^{2}=0.9744(p<0.0001)$ and $\mathrm{Y} \max =22.9(\mathrm{X}$ concentration) (Table 3). However, FER, PER, and PR of fish was not significantly $(p>0.05)$ influenced by the experimental diets.

CF of fish fed the JMM0 and JMM1 diets was significantly $(p<0.05)$ lower than that of fish fed the JMM3, JNM5, and JMM10 diets. The following correlation between CF (Y) and JMM (X) levels in diets was obtained: $\mathrm{Y}=-0.0007 \mathrm{X}^{2}+0.0166 \mathrm{X}$ $+1.4204, \mathrm{R}^{2}=0.9434(p<0.0001)$ and $\mathrm{Y} \max =11.9$ (X concentration). However, HSI of fish was not significantly $(p>0.05)$ influenced by dietary inclusion levels of JMM.

The chemical composition of the whole body of fish was not significantly $(p>0.05)$ influenced by the experimental diets (Table 4).

\section{Discussion}

Quadratic responses (weight gain, SGR, feed consumption and $\mathrm{CF}$ ) of rockfish depending on JMM levels in this study indicated that dietary increased levels of JMM acting as feed

Table 2. Survival, weight gain and specific growth rate (SGR) of rockfish fed the experimental diets containing various concentrations of jack mackerel meal (JMM) for 8 weeks

\begin{tabular}{llllll}
\hline Experimental diets & Initial weight (g/fish) & Final weight (g/fish) & Survival (\%) & Weight gain (g/fish) & SGR $(\% /$ day) \\
\hline JMM0 & $5.3 \pm 0.00$ & $23.1 \pm 0.06^{\mathrm{e}}$ & $100.0 \pm 0.00$ & $17.8 \pm 0.07^{\mathrm{e}}$ & $2.64 \pm 0.006^{\mathrm{e}}$ \\
JMM1 & $5.3 \pm 0.01$ & $24.3 \pm 0.02^{\mathrm{d}}$ & $100.0 \pm 0.00$ & $19.0 \pm 0.03^{\mathrm{d}}$ & $2.72 \pm 0.005^{\mathrm{d}}$ \\
JMM3 & $5.3 \pm 0.00$ & $24.8 \pm 0.05^{\mathrm{c}}$ & $100.0 \pm 0.00$ & $19.5 \pm 0.05^{\mathrm{c}}$ & $2.76 \pm 0.004^{\mathrm{c}}$ \\
JMM5 & $5.3 \pm 0.01$ & $26.0 \pm 0.04^{\mathrm{b}}$ & $100.0 \pm 0.00$ & $20.7 \pm 0.03^{\mathrm{b}}$ & $2.84 \pm 0.002^{\mathrm{b}}$ \\
JMM10 & $5.3 \pm 0.01$ & $28.1 \pm 0.08^{\mathrm{a}}$ & $100.0 \pm 0.00$ & $22.8 \pm 0.07^{\mathrm{a}}$ & $2.98 \pm 0.003^{\mathrm{a}}$ \\
\hline
\end{tabular}

Values (means of triplicate \pm SE) in the same column with same superscript letter are not significantly different $(p>0.05$ ).

${ }^{1)}$ SGR (\%/day) $=($ Ln final weight of fish - Ln initial weight of fish $) \times 100 /$ days of feeding trial. 
Table 3. Feed consumption (g/fish), feed utilization, condition factor (CF) and hepatosomatic index (HSI) of rockfish fed the experimental diets containing various concentrations of jack mackerel meal (JMM) for $\mathbf{8}$ weeks

\begin{tabular}{|c|c|c|c|c|c|c|}
\hline Experimental diets & Feed consumption (g/fish) & FER $^{1)}$ & $\mathrm{PER}^{2)}$ & $\mathrm{PR}^{3)}$ & $\mathrm{CF}^{4)}$ & $\mathrm{HSI}^{5)}$ \\
\hline JMMO & $17.2 \pm 0.05^{\mathrm{e}}$ & $1.04 \pm 0.006$ & $1.99 \pm 0.011$ & $35.4 \pm 0.18$ & $1.43 \pm 0.005^{d}$ & $2.85 \pm 0.005$ \\
\hline JMM1 & $18.4 \pm 0.05^{d}$ & $1.03 \pm 0.001$ & $1.98 \pm 0.002$ & $35.5 \pm 0.18$ & $1.43 \pm 0.002^{d}$ & $2.85 \pm 0.002$ \\
\hline JMM3 & $18.8 \pm 0.10^{c}$ & $1.04 \pm 0.005$ & $1.99 \pm 0.009$ & $35.1 \pm 0.27$ & $1.45 \pm 0.003^{c}$ & $2.85 \pm 0.002$ \\
\hline JMM5 & $20.1 \pm 0.05^{b}$ & $1.03 \pm 0.003$ & $1.99 \pm 0.006$ & $35.2 \pm 0.36$ & $1.50 \pm 0.002^{b}$ & $2.84 \pm 0.003$ \\
\hline JMM10 & $22.0 \pm 0.05^{\mathrm{a}}$ & $1.04 \pm 0.002$ & $2.00 \pm 0.004$ & $35.0 \pm 0.23$ & $1.52 \pm 0.006^{\mathrm{a}}$ & $2.85 \pm 0.002$ \\
\hline
\end{tabular}

Values (means of triplicate $\pm \mathrm{SE}$ ) in the same column with same superscript letter are not significantly different $(p>0.05)$.

${ }^{1)}$ Feed efficiency ratio (FER) = Weight gain of fish / feed consumption.

2) Protein efficiency ratio $(\mathrm{PER})=$ Weight gain of fish / protein consumption

${ }^{3)}$ Protein retention $(\mathrm{PR})=$ Protein gain $\times 100 /$ protein consumption.

${ }^{4)}$ Condition factor $\left(\mathrm{CF}, \mathrm{g} / \mathrm{cm}^{3}\right)=$ Total body weight $\times 100 /$ total length

${ }^{5)}$ Hepatosomatic index $(\mathrm{HSI})=$ Liver weight $\times 100 /$ total body weight.

Table 4. Proximate composition (\%) of the whole body rockfish fed the experimental diets containing various concentrations of jack mackerel meal (JMM) for 8 weeks

\begin{tabular}{lllll}
\hline Experimental diets & Moisture & Crude protein & Crude lipid & Ash \\
\hline JMM0 & $69.1 \pm 0.16$ & $17.4 \pm 0.01$ & $8.0 \pm 0.08$ & $4.6 \pm 0.06$ \\
JMM1 & $69.0 \pm 0.10$ & $17.5 \pm 0.09$ & $8.0 \pm 0.15$ & $4.4 \pm 0.11$ \\
JMM3 & $69.1 \pm 0.06$ & $17.3 \pm 0.07$ & $8.1 \pm 0.13$ & $4.0 \pm 0.08$ \\
JMM5 & $68.8 \pm 0.23$ & $17.4 \pm 0.10$ & $8.0 \pm 0.12$ & $4.3 \pm 0.14$ \\
JMM10 & $69.1 \pm 0.15$ & $17.3 \pm 0.07$ & $8.0 \pm 0.09$ & $4.0 \pm 0.08$ \\
\hline
\end{tabular}

attractants and/or stimulants improved growth performance, feed consumption and CF of fish. This was also well proved by Kim \& Cho (2019)'s study, in which dietary inclusion of JMM at $5 \%$ among 5 ingredients showing strong attractiveness to rockfish achieved improvement in growth performance (weight gain, SGR and CF) of fish directly reflected from improved feed consumption. Kim et al. (2019) also showed that JMM achieved the strongest attractiveness to rockfish among 16 crude feed ingredients and difference in free amino acids, such as histidine and leucine in FMs could bring about that in feed attractability or palatability of fish.

As the maximum value in quadratic responses of each dependent variable of weight gain, SGR, feed consumption and CF versus dietary JMM levels was estimated to be $26.0 \%, 21.7 \%$, $22.9 \%$, and $11.9 \%$, respectively, dietary optimum level of JMM for weight gain, SGR and feed consumption appeared to be approximately $22 \%-26 \%$, but $12 \%$ for CF, respectively. Feasibility of incorporated JMM in commercial extruded pellet should be evaluated as JMM is one of the most expensive FMs commonly used in fish feed. Nevertheless, improved weight gain, SGR, feed consumption and CF of rockfish depending on dietary inclusion levels of JMM indicate that desirable effect of manipulation of JMM in diets on growth performance and feed consumption of rockfish.

Refstie et al. (2004) reported that dietary inclusion levels of fish protein hydrolysate tended to improve growth, feed intake and FER of Atlantic salmon (Salmo salar) when fish were fed with extruded pellets containing various levels (5\%, 10\% and 15\%) of fish protein hydrolysate instead of FM for 68 days. Dietary inclusion of tuna viscera hydrolysate also tended to increase feed consumption and growth of Asian sea bass (Lates calcarifer), but achieved relatively poor feed consumption and growth over fish fed a FM-based diet when FM was completely substituted with poultry by-product meals supplemented with tuna viscera hydrolysate at $1 \%, 2 \%, 3 \%$, and $4 \%$ acting as feed attractants in diets (Chotikachinda et al., 2013). Weight gain and feed consumption of turbot fed diets substituting 75\% FM with rapeseed protein concentrate with increased amount of blue mussel meal were improved when 50\% and 75\% FM were substituted with rapeseed protein concentrate supplemented with blue mussel meal acting as feed attractants at $2 \%, 4 \%$, and $8 \%$ in diets (Nagel et al., 2014). Paul et al. (2004) demonstrated that dietary inclusion of $1 \%$ terrestrial plant-originated feed attractants composed of $25 \%$ Trigonella forenum graceum, 15\% Myristic fragrans, 15\% Piper betel, 20\% Psoralea corylifolia and 25\% Campheria sp. improved daily growth rate of rohu (Labeo rohita). Increased dried basil leaves in diets improved feed intake and weight gain of hybrid tilapia (Oreochromis niloticus $\times$ O. niloticus aureus) fingerlings when $0.5 \%, 1 \%$, and $2 \%$ dried basil leave acting as feed attractants were included in diets (El-Dakar et al., 2008).

Improved weight gain, SGR and CF of rockfish with dietary inclusion levels of JMM, but no difference in feed efficiency (FER, PER, and PR) among diets in this study indicated that improved growth performance (weight gain, SGR and CF) of fish was 
directly reflected from improved feed consumption, and JMM acted as feed attractants and/or stimulants to rockfish. Similarly, improved growth performance and CF of rockfish was directly reflected from improved feed consumption, but no difference in feed efficiency was also observed when FMs having different feeding attractiveness to rockfish were included at 5\% in diets (Kim \& Cho, 2019). Similarly, FER of turbot was not different among diets substituting FM with rapeseed protein concentrate supplemented with various levels of blue mussel meal (Nagel et al., 2014). Dietary inclusion of squid liver paste improved feed consumption of juvenile genetically improved farmed tilapia (Oreochromis sp.), but did not affect FER (Zou et al., 2016).

Dietary inclusion levels of JMM did not alter HSI of fish in this study. Similarly, supplementation of feed attractants (fish soluble, krill meal, squid meal and their combination) in low FM-diets effectively improved feed consumption and growth of red sea bream, but did not alter HSI (Kader et al., 2010). Kader et al. (2012) also reported that low FM diets supplemented with feed attractants improved feed consumption and growth of red sea bream, but did not affect HSI when FM up to 30\% were replaced with dehulled soybean meal supplemented with feed attractants. Dietary inclusion of any feed stimulants (the mixture of nucleotides, taurine or squid liver paste) had no effect on HSI of tilapia (Zou et al., 2016). Tusche et al. (2011) also demonstrated that HSI of rainbow trout was not affected by either dietary concentrations or sources of feed attractants. However, a contrast result that dietary inclusion of mussel meal acting as feed stimulants changed both CF and HSI of common sole was also reported (Mongile et al., 2015).

The whole body composition of rockfish was not influenced by dietary inclusion levels of JMM in this study. The consistent result, in which the chemical composition of the whole body or carcass of fish was not altered by dietary inclusion of feed attractants and/or stimulants was also reported (Kader et al., 2012; Nagel et al., 2014; Paul et al., 2004; Zou et al., 2016).

\section{Conclusion}

Weight gain, SGR, feed consumption and CF of rockfish improved with dietary inclusion levels of JMM acting as feed attractants and/or stimulants.

\section{Competing interests}

No potential conflict of interest relevant to this article was reported.

\section{Funding sources}

This work was supported by the National Research Foundation of Korea (NRF) grant funded by the Korean government (No. 2020R1A2C1009903).

\section{Acknowledgements}

Not applicable.

\section{Availability of data and materials}

Datasets of the study can be available from the corresponding author upon reasonable request.

\section{Ethics approval and consent to participate}

This article does not require IRB/IACUC approval because there are no human and animal participants.

\section{ORCID}

Seong Il Baek

https://orcid.org/0000-0002-6527-0971

Sung Hwoan Cho https://orcid.org/0000-0002-6973-5449

Hee Sung Kim https://orcid.org/0000-0002-8627-615X

\section{References}

Abidi SF, Khan MA. Dietary threonine requirement of fingerling Indian major carp, Labeo rohita (Hamilton). Aquac Res. 2008;39:1498-505.

Association of Official Analytical Chemists [AOAC]. Official methods of analysis. 15th ed. Arlington, VA: AOAC; 1990.

Carr WES, Netherton Iii JC, Gleeson RA, Derby CD. Stimulants of feeding behavior in fish: analyses of tissues of diverse marine organism. Biol Bull. 1996;190:149-60.

Cha SH, Lee JS, Song CB, Lee KJ, Jeon YJ. Effects of chitosan-coated diet on improving water quality and innate immunity in the olive flounder, Paralichthys olivaceus. Aquaculture. 2008;278:110-8.

Cho SH, Lee SM, Lee JH. Effects of the extruded pellets and raw fish-based moist pellet on growth and body composition of flounder, Paralichthys olivaceus L. for 10 months. J Aquac. 2005;18:60-5.

Chotikachinda R, Tantikitti C, Benjakul S, Rustad T, Kumarnsit E. Production of protein hydrolysates from skipjack tuna (Katsuwonus pelamis) viscera as feeding attractants for Asian seabass (Lates calcarifer). Aquac Nutr. 2013;19:773-84.

Ekanem SB. Effects of feeding frequency, moist and dry feeds on the growth of Chrysichthys nigrodigitatus Lacépède and 
on pond water quality. Aquac Res. 1996;27:107-12.

El-Dakar A, Hassanien G, Gad S, Sakr S. Use of dried basil leaves as a feeding attractant for hybrid tilapia, Oreochromis niloticus $\times$ Oreochromis aureus, fingerlings. Med Aquac J. 2008;1:35-44.

Kader MA, Bulbul M, Koshio S, Ishikawa M, Yokoyama S, Nguyen BT, et al. Effect of complete replacement of fishmeal by dehulled soybean meal with crude attractants supplementation in diets for red sea bream, Pagrus major. Aquaculture. 2012;350-353:109-116.

Kader MA, Koshio S, Ishikawa M, Yokoyama S, Bulbul M. Supplemental effects of some crude ingredients in improving nutritive values of low fishmeal diets for red sea bream, Pagrus major. Aquaculture. 2010;308:136-44.

Kasumyan AO, Døving KB. Taste preferences in fishes. Fish Fish. 2003;4:289-347.

Kasumyan AO, Morsi AMK. Taste sensitivity of common carp Cyprinus carpio to free amino acids and classical taste substances. J Ichthyol. 1996;36:391-403.

Kim HS, Baek SI, Lee KW, Jeong HS, Cho SH. Attractiveness of various protein sources to juvenile rockfish (Sebastes schlegeli, Hilgendorf 1880). J Appl Aquac. 2019;32:205-20.

Kim HS, Cho SH. Dietary inclusion effect of feed ingredients showing high feeding attractiveness to rockfish (Sebastes schlegeli Hilgendorf 1880) on the growth performance, feed utilization, condition factor and whole body composition of fish (II). Comp Biochem Physiol A Mol Integr Physiol. 2019;231:66-73.

Kim KW, Wang X, Han K, Bai SC, Kang JC. Optimum dietary protein level and protein-to-energy ratio for growth of juvenile Korean rockfish Sebastes schlegeli. J World Aquac Soc. 2007;35:305-14.

Kim KW, Wang XJ, Bai SC. Reevaluation of the optimum dietary protein level for the maximum growth of juvenile Korean rockfish, Sebastes schlegeli (Hilgendorf). Aquac Res. 2001;32:119-25.

Kolkovski S, Czesny S, Dabrowski K. Use of krill hydrolysate as a feed attractant for fish larvae and juveniles. J World Aquac Soc. 2000;31:81-8.

Korean Statistical Information Service [KOSIS]. Statistical DB. Daejeon, Korea: KOSIS; 2021.

Lee PG, Meyers SP. Chemoattraction and feeding stimulation in crustaceans. Aquac Nutr. 1996;2:157-64.

Mackie AM. Identification of the gustatory feeding stimulants. In: Hara TJ editor. Fish chemoreception. London, UK:
Chapman and Hall; 1982. p.275-91.

Mai K, Li H, Ai Q, Duan Q, Xu W, Zhang C, et al. Effects of dietary squid viscera meal on growth and cadmium accumulation in tissues of Japanese seabass, Lateolabrax japonicus (Cuvier 1828). Aquac Res. 2006;37:1063-69.

Mongile F, Mandrioli L, Mazzoni M, Pirini M, Zaccaroni A, Sirri R, et al. Dietary inclusion of mussel meal enhances performance and improves feed and protein utilization in common sole (Solea solea, Linnaeus, 1758) juveniles. J Appl Ichthyol. 2015;31:1077-85.

Nagel F, von Danwitz A, Schlachter M, Kroeckel S, Wagner C, Schulz C. Blue mussel meal as feed attractant in rapeseed protein-based diets for turbot (Psetta maxima L.). Aquac Res. 2014;45:1964-78.

Olsén KH, Lundh T. Feeding stimulants in an omnivorous species, crucian carp Carassius carassius (Linnaeus 1758). Aquac Rep. 2016;4:66-73.

Paul BN, Sarkar S, Mukhopadhyay PK, Mohanty SN. Effect of dietary attractant on feed utilisation and growth of rohu Labeo rohita (Ham.) fry. Anim Nutr Feed Technol. 2004;4:145-52.

Refstie S, Olli JJ, Standal H. Feed intake, growth, and protein utilisation by post-smolt Atlantic salmon (Salmo salar) in response to graded levels of fish protein hydrolysate in the diet. Aquaculture. 2004;239:331-49.

Sun L, Chen H, Huang L, Wang Z. Growth, faecal production, nitrogenous excretion and energy budget of juvenile cobia (Rachycentron canadum) relative to feed type and ration level. Aquaculture. 2006;259:211-21.

Tusche K, Berends K, Wuertz S, Susenbeth A, Schulz C. Evaluation of feed attractants in potato protein concentrate based diets for rainbow trout (Oncorhynchus mykiss). Aquaculture. 2011;321:54-60.

Yacoob SY, Browman HI. Olfactory and gustatory sensitivity to some feed-related chemicals in the Atlantic halibut (Hippoglossus hippoglossus). Aquaculture. 2007;263:303-9.

Zou Q, Huang Y, Pan Q, Li Y, Wang G, Zhao H, et al. Effects of supplemental nucleotides, taurine, and squid liver paste on feed intake, growth performance, serum biochemical parameters, and digestive enzyme activities of juvenile GIFT tilapia (Oreochromis sp.) fed low fishmeal diets. Isr J Aquac-Bamidgeh. 2016;68:1273-81. 